\title{
CONSCIENTIZAÇÃO SOCIOAMBIENTAL A RESPEITO DA GERAÇÃO DE RESÍDUOS SÓLIDOS URBANOS (RSU)
}

\author{
Fernando Cassas \\ Universidade Federal de São Paulo \\ fernando.csm90@gmail.com
}

\begin{abstract}
Resumo
O projeto visou promover uma reflexão socioambiental a respeito do lixo doméstico gerado no entorno das unidades da UNIFESP, Campus Diadema, SP. Foram realizadas atividades educativas envolvendo moradores do município de Diadema e discentes de graduação dos sete cursos oferecidos na Universidade; sendo elas: mutirão de limpeza "katasukata", pedágio ecológico, visitas às escolas, trote ecológico e evento na Praça. A partir dessas cinco atividades desenvolvidas ao longo de dez meses no ano de 2014, a população envolvida com a temática: "descarte de lixo doméstico" foi sensibilizada e a educação ambiental, divulgada. Diante da receptividade dos discentes e da comunidade conclui-se que estas ações podem ser produtivas para a reflexão e mudança de comportamento se desenvolvidas com periodicidade.

Palavras-chave: Educação ambiental. Resíduos sólidos urbanos. Lixo doméstico. Mutirão.
\end{abstract}

\section{ENVIRONMENTAL AWARENESS ABOUT THE MUNICIPAL SOLID WASTE GENERATION}

\begin{abstract}
The project aimed to promote environmental reflection on the household waste generated in the vicinity of the units UNIFESP, Campus Diadema, SP. Educational activities involving residents of the city of Diadema and undergraduate students of the seven courses offered at the University were held; these being: clean-up "katasukata" ecological toll, visits to schools, ecological and trotting event in the Square. From these five activities developed over ten months in 2014, the population involved with the theme, "household waste disposal" was sensitized and environmental education disclosed. Faced with the receptivity of the students and the community is concluded that these actions can be productive for reflection and change of behavior developed at intervals.
\end{abstract}

Keywords: Environmental education. Urban solid waste. Domestic waste. Effort.

\section{CONCIENTIZACION SOCIOAMBIENTAL SOBRE LA GENERACIÓNDE RESIDUOS SÓLIDOS URBANOS (RSU)}

\section{Resumen}

El proyecto tuvo como objetivo promover la reflexión ambiental sobre los residuos domésticos generados en las proximidades de las unidades de la UNIFESP, Campus Diadema, SP. Fueron realizadas actividades educativas envolviendo residentes de la municipalidad de Diadema y estudiantes universitarios de los siete cursos que se ofrecen en la Universidad, se llevaron a cabo, a saber: limpieza "katasukata", peaje ecológico, visitas a escuelas e evento en la plaza. A partir de estas cinco actividades desarrolladas a lo largo de diez meses en 2014, la población involucrada con el tema, "desechos del hogar" se sensibilizó y educación ambiental divulgada. Frente a la receptividad de los estudiantes y la comunidad se concluye que estas acciones pueden ser productivas para la reflexión y el cambio de comportamiento desarrollado a intervalos.

Palabras clave: Educación ambiental. Residuos sólidos urbanos. Residuos domésticos. 
Conscientização socioambiental a respeito da geração de resíduos sólidos urbanos (RSU)

\section{INTRODUÇÃO}

Os resíduos sólidos urbanos (RSUs), vulgarmente conhecidos por lixo, resultam da atividade doméstica e comercial da rotina das cidades. Sua composição varia de acordo com o perfil de cada sociedade, da sua situação socioeconômica, das condições e hábitos de vida locais. Os resíduos geralmente são classificados como: Matéria orgânica; restos de comida; Papel e papelão; jornais, revistas, caixas e embalagens. Plásticos; garrafas, garrafões, frascos e outras embalagens. Vidro; garrafas, frascos, copos. Metais; latas. E Outros; roupas, óleos de cozinha e óleos de motor, bem como resíduos informáticos e tecnológicos.

Em média, o lixo doméstico no Brasil, segundo Jardim e Wells (1995) é composto por: $65 \%$ de matéria orgânica; $25 \%$ de papel; $4 \%$ de metal; 3\% de vidro e 3\% de plástico. Apesar de atender a legislação específica de cada município, o lixo comercial até $50 \mathrm{~kg}$ ou litros e o domiciliar são de responsabilidade das prefeituras, enquanto os demais são de responsabilidade do próprio gerador. A preocupação mundial em relação aos problemas ligados aos RSUs consta no capítulo 21 do documento produzido na Conferência das Nações Unidas (ONU) sobre Meio Ambiente e Desenvolvimento (CNUMAD), a Eco-92. Este documento propõe como um dos principais compromissos da humanidade para futuras gerações o Desenvolvimento Sustentável, que deveria conciliar justiça social, eficácia econômica e equilíbrio ambiental (UN, 1999). O aumento na geração de RSU é um problema atual e crescente em diversos países da América Latina e Caribe (ALC) (Rego et al., 2002). De um modo geral, nos últimos 40 anos este aumento ocorreu devido ao consumo exacerbado de produtos oriundos dos diversos segmentos da economia, à produção indiscriminada de embalagens não recicláveis, aos hábitos alimentares artificializados (fast-food e congelados), ao lixo doméstico, industrial, comercial, e dos serviços de saúde.

Existem dados apontando para uma taxa de geração per capita diária de 0,3 a 0,8kg/habitantes/dia de Resíduos Sólidos Domiciliares e de 0,5 a 1,2 kg/habitantes/dia de Resíduos Sólidos Municipais na região da América Latina e Caribe (Acurioet al., 1997). Segundo o IBGE, em 2006, o Brasil gerava 228.413 toneladas diárias de resíduos sólidos. Isso implica numa produção de 1,2 kg/habitante (IBGE, 2006). Por outro lado, estima-se que 30-50\% dos resíduos gerados nas cidades dos países em desenvolvimento não são recolhidos (OPS, 1993). Segundo o IBGE (2011), dos 5.570 municípios brasileiros, apenas 32,3\% (1.796 municípios) possuíam programa, projeto ou ação de coleta seletiva de lixo em atividade naquele ano. A região Sul era a que possuía a maior proporção desses municípios, 55,8\% (663), seguida da região Sudeste, com $41,5 \%$ (693). Por outro lado, Norte e Nordeste possuíam as maiores proporções de municípios 
Conscientização socioambiental a respeito da geração de resíduos sólidos urbanos (RSU)

sem programas, $62,8 \%$ (282) e 62,3\% (1.118), respectivamente. No entanto, na região Norte, $79,1 \%$ (355) dos municípios se declararam sem programa mas com projeto, ao passo que no Nordeste esse percentual se restringiu a 17,7\% (317). Ainda segundo esta pesquisa, apenas 30,7\% (1.711) das cidades tinha conhecimento das prefeituras acerca da existência de cooperativas ou associações de catadores de materiais recicláveis. A geração de RSUs promove implicações no ambiente e na saúde. Alguns estudos realizados no Brasil demonstram uma possível relação positiva entre o manejo inadequado das RSUs e algumas morbidades (Heller, 1995; Rêgo, 1996; Moraes, 1997; Catapreta e Heller, 1999; Rêgo et al., 2002).

Da mesma forma, segundo Mucellin e Bellini, (2008), materiais sem utilidade se amontoam indiscriminada e desordenadamente, muitas vezes em locais indevidos como lotes baldios, margens de estradas, fundos de vale e margens de lagos e rios; promovendo um comprometimento ambiental e visual da cidade. No Brasil, a Lei 9.795 de 27/04/99, dispõe sobre a Educação Ambiental (EA) e institui a Política Nacional de Educação Ambiental, que é definida como: "processos por meio dos quais o indivíduo e a coletividade constroem valores sociais, conhecimentos, habilidades, atitudes e competências voltadas para a conservação do meio ambiente, bem de uso comum do povo, essencial à sadia qualidade de vida e sua sustentabilidade."

Embora a EA seja definida como um processo dinâmico integrativo, transformador, participativo, abrangente, globalizador, permanente e contextualizador, há um aspecto que é praticamente escamoteado nestas definições. Trata-se de conceber a Educação como um instrumento no processo de gestão ambiental, postulando-se a necessidade de criação de espaços democráticos de exercício do poder de gestão (Zanetti e Sá, 2002). Os mesmos autores argumentam que tal concepção implicaria em se prever formas de compartilhamento com as populações locais envolvidas nas questões ambientais das informações necessárias à compreensão da complexidade dessas questões, bem como a criação de espaços de decisão quanto às políticas públicas a serem adotadas. Alguns autores, tais como (Carvalho, 1998; Quintas, 2000), discutem a importância da EA como ferramenta de mudança de paradigma no manejo adequado dos RSUs.

Vários municípios brasileiros têm-se dedicado a programas de coleta seletiva de lixo e outras atividades no âmbito da EA: no estado de São Paulo, o municípios de Campinas (Prefeitura Municipal de Campinas, 2013); no estado de Santa Catarina, em Bombinhas (Prefeitura Municipal de Bombinhas, 2013); no Rio Grande do Sul, em Garibaldi (Prefeitura Municipal de Garibaldi, 2013). Estes são apenas alguns dos muitos exemplos que poderiam ser apontados. 
Diadema constituiu-se como município em 1958, e está distante $17 \mathrm{~km}$ do marco zero de São Paulo, localizado na Praça da Sé (Figura 1). Formada por 13 bairros (macro-regiões), seu território representa 4,94\% de todo o território do ABCD paulista e 0,01\% do território estadual. Sendo considerada um dos maiores e mais importantes reservatórios de água da Região Metropolitana de São Paulo, a represa Billings faz limite com a Bacia Hidrográfica de Guarapiranga e ao sul com a Serra do Mar. Tem aproximadamente $100 \mathrm{Km}^{2}$ e sua bacia hidrográfica estende-se por mais de $500 \mathrm{~km}^{2}$, nos municípios de Ribeirão Pires, Diadema, Rio Grande da Serra, São Bernardo do Campo, Santo André e São Paulo (SABESP, 2013). Ao redor da represa existem hoje quase um milhão de pessoas e segundo relatório da EMPLASA (Empresa Paulista de Planejamento Metropolitano, 2013) de 1990 para 2000, a população ribeirinha cresceu 7\% ao ano (Catão e Negrin, 2013).

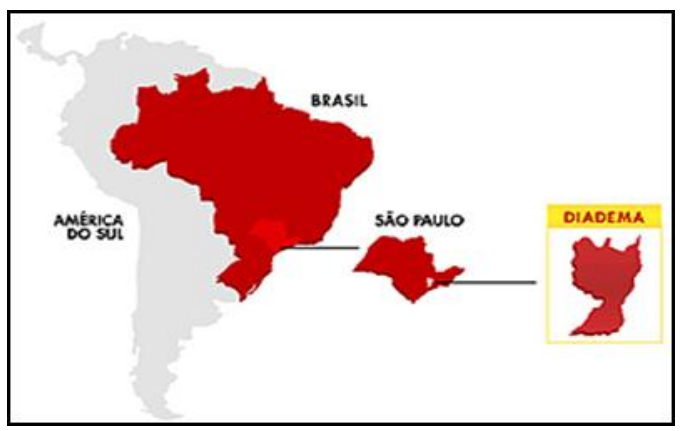

Ilustração 1 - Localização do município de Diadema (mapa da direita), no estado de São Paulo (mapa do meio), no Brasil (mapa da esquerda).

Fonte: Prefeitura Municipal de Diadema, 2013.

O município de Diadema possui, em média, $10 \mathrm{~m}^{2}$ de área verde por habitante, concentrada em áreas de proteção e recuperação aos mananciais. A maioria da população encontra-se na faixa etária dos 20 aos 29 (IBGE Datasus, 2013). Com uma taxa de crescimento anual de 2,48\% sua população atual é de 406.718 habitantes (IBGE Datasus, 2013). Diadema apresenta uma densidade demográfica de 12.536,99 habitantes por $\mathrm{Km}^{2}$, uma das maiores do país. A parcela economicamente ativa é de 215.000 pessoas e possui uma taxa de analfabetismo de 6,8\%. (Prefeitura Municipal de, 2013). Seu Índice de Desenvolvimento Humano (IDH) é de 0.757, segundo o Atlas de Desenvolvimento Humano/PNUD (2013). O abastecimento de água domiciliar atinge 99,1\% das casas, enquanto 92,0\% possui rede de esgoto e 99,6\% tem coleta pública de lixo (Prefeitura Municipal de, 2013). Ainda segundo a mesma fonte, em 2008 a principal causa de morte (segundo o CID-10) foi por doenças do aparelho circulatório, seguido por outras causas externas de morbidade e mortalidade.

A UNIFESP, Campus Diadema, foi criada em 2006 e oferece atualmente sete cursos de graduação: Ciências Ambientais, Ciências Biológicas, Farmácia e Bioquímica, Química Industrial, 
Conscientização socioambiental a respeito da geração de resíduos sólidos urbanos (RSU)

Química, Engenharia Química e Licenciatura Plena em Ciências - alguns deles ocorrem em período integral e outros, no noturno. Sua estrutura física está distribuída em quatro quatro unidades no município de Diadema, são elas: Antônio Doll, José Alencar, José de Filippi e Manuel da Nóbrega. Estas unidades localizam-se tanto próximo à comunidade urbana, quanto à periférica, proporcionando uma interação entre a comunidade acadêmica com os moradores da cidade.

A desigualdade social, econômica e a falta de informação à população geram muitos problemas sociais e ambientais (Gravinatto e Rodrigues, 2000). A ocupação irregular, a deposição de lixo em locais inapropriados é um exemplo visível destes problemas na região de Diadema. Dado este cenário, medidas como atividades educacionais sobre noção do impacto individual no ambiente são produtivas para promover e difundir a consciência ambiental, o que acarreta, ao longo do tempo, no aumento do desenvolvimento da cidade e do seu IDH. No bairro de Eldorado no Município de Diadema, por exemplo, há muitas moradias irregulares em áreas de manancial. Os resíduos sólidos que são descartados de forma inadequada, tanto lá quanto em muitos outros municípios, acabam contaminando os solos, córregos e lagos, o que provoca em um aumento do risco ambiental e grau de toxicidade (Braga et al., 2005).

O processo de construção do conhecimento coletivo em uma determinada cultura é variável conforme a visão de mundo já estabelecida historicamente. No entanto, algumas delas precisam ser alteradas devido a uma necessidade vigente, portanto utilizar os conhecimentos e instrumentos regionais é importante para criar e difundir um novo comportamento. Dessa forma é preciso identificar as interpretações que possuem caráter social e valorizá-las por meio de ações educativas com o consentimento da população local. A transmissão de informação e a construção do conhecimento coletivo é um processo que envolve tempo e a promoção de atividades que atraiam o público para a problemática e demonstrem a relevância do papel individual para o melhor desenvolvimento da qualidade de vida. Os conhecimentos de mundo e valores já existentes em cada indivíduo devem ser respeitados, entretanto é função da educação ambiental alertar e evidenciar os riscos que podem existir em determinados comportamentos. O foco é elucidar por meio de exemplos práticos que toda atitude gera uma consequência. Neste sentido, este projeto se justifica por viabilizar a integração dos docentes e discentes da UNIFESP com a população de Diadema, mostrando a importância do compromisso que deve ser estabelecido com seu ambiente, visando a melhoria da qualidade de vida geral da cidade. Para tanto, serão utilizadas abordagens e instrumentos da EA para despertar o interesse da população por estas 
questões, sejam elas: atividades lúdicas, interativas e sensibilizadoras que levam o conhecimento para o sujeito desenvolver o senso crítico num contexto econômico-político-ambiental.

\section{Objetivos}

O projeto visou proporcionar uma reflexão socioambiental a respeito do lixo doméstico que é gerado no entorno das unidades da UNIFESP, Campus Diadema, SP, desenvolvidas ao longo de dez meses no ano de 2014.

\section{MATERIAIS E MÉTODOS}

Para a implantação das cinco atividades expostas a seguir a equipe do projeto formou uma Comissão Organizadora cujos membros foram discentes dos cursos de graduação da UNIFESP. A comissão teve o papel de estruturar, divulgar e realizar as atividades. Após a divulgação os demais discentes interessados em participar das atividades realizaram a sua inscrição. Os participantes receberam um certificado que podia ser validado como horas complementares pelos seus respectivos cursos; o número de horas variou de acordo com cada ação.

Para a estruturação de cada atividade foram realizadas reuniões semanais para que a equipe pudesse tomar contato com os autores e artigos oriundos de outras experiências, relacionados ao tema. Dessa forma, foi possível embasar os discentes para a produção dos folders, palestras e questionários a serem utilizados de forma específica. Durante o processo de divulgação, a utilização de mídias sociais foram fundamentais para convocar os discentes interessados. A comunidade local foi convidada a participar mediante cartazes com data, hora e local. Também foi realizada uma parceria som a Secretaria do Meio Ambiente (SEMA) da cidade. No decorrer de cada ação os envolvidos sensibilizaram a população por meio de cartilhas, cartazes, folders, palestras com a temática ambiental. Em todas as atividades, a equipe e a Comissão Organizadora estavam vestindo coletes com o emblema da Unifesp e o nome do projeto. Sendo esta uma forma de divulgar e identificar as ações da universidade, evidenciando o seu papel atuante em atividades de extensão. Seguem abaixo as cinco atividades que foram realizadas ao longo dos dez meses de projeto.

\section{Mutirão de limpeza: "Katasukata"}


Conscientização socioambiental a respeito da geração de resíduos sólidos urbanos (RSU)

A exemplo de outros projetos de Educação Ambiental envolvendo mutirões de coleta de lixo (Reigada e Reis, 2004; Amador e Palma, 2013), esta atividade consistiu em um mutirão realizado no condomínio Praia Vermelha, que circunda a represa Billings, próximo à Unidade da UNIFESP José de Filippi, no bairro de Eldorado. O evento reuniu os docentes e discentes, bem como os moradores da região. Nesta data a equipe e a Comissão Organizadora estavam munidos de luvas de proteção e sacos para recolhimento do lixo. Após ouvir uma breve orientação por parte da equipe, os membros da Comissão realizaram o recolhimento dos materiais presentes na represa. Posteriormente, montou-se uma exposição, nas dependências da UNIFESP, dos materiais coletados e fotos de onde foram retirados, para evidenciar e sensibilizar os demais discentes, funcionários e docentes do campus com a problemática ambiental.

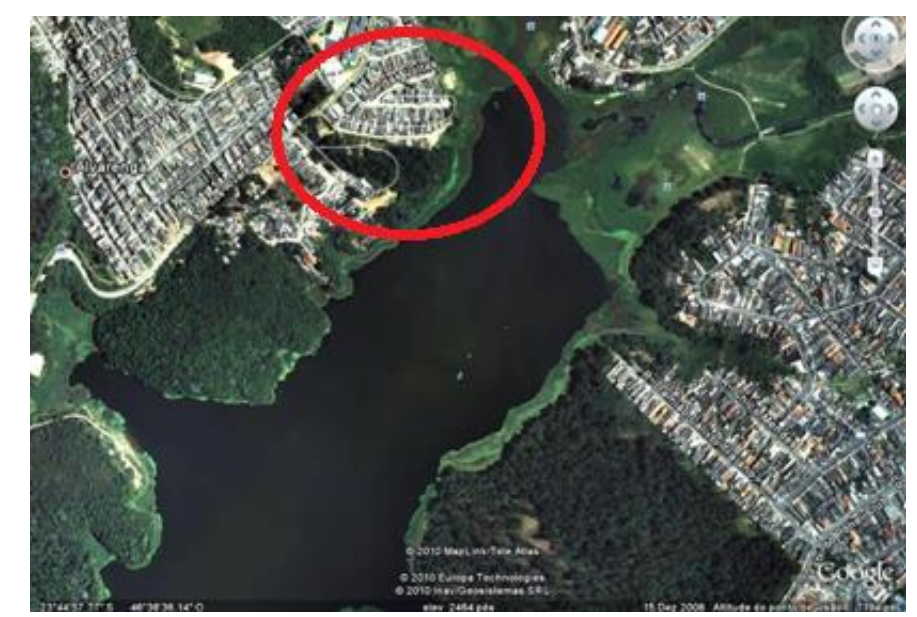

Ilustração 2 - Localização do condomínio Praia Vermelha (círculo vermelho), à beira da Represa Billings, Bairro Eldorado, no município de Diadema, São Paulo.

Fonte: Site Cuidando do verde - Amigos da natureza, 2013.

\section{Visitas às escolas}

Nesta atividade, a equipe e a Comissão Organizadora visitaram uma escola estadual e uma ONG no município de Diadema; ministraram palestras com a temática ambiental evidenciando os processos de extração, produção, consumo e descarte dos resíduos sólidos domiciliares para evidenciar que não só a coleta seletiva é solução para este problema. A decisão de montar-se uma palestra com o foco apresentado acima adveio das discussões em grupo. No lugar de apenas enfatizar a importância da coleta seletiva e a separação adequada dos materiais, procurou-se mostrar a origem de cada resíduo e de cada embalagem a ser reciclada. Sendo esta uma forma de embasar os ouvintes para que eles pudessem extrair as suas concepções dos resíduos, sejam elas de reduzir o consumo e da necessidade do descarte adequado. Dessa forma estruturou-se a apresentação em três grandes momentos: 1) Iniciou-se apresentando a definição dos RSU's dentro de um contexto econômico-político-ambiental. Falou-se dos processos de extração, 
produção, consumo e descarte. 2) Apresentou-se os 3 tipos mais comuns de RSU's (agrícolas, domiciliares e industriais). Mostrou-se a classificação destes em orgânicos e inorgânicos. Após a apresentação destes conceitos mostrou-se a origem de cada embalagem e os processos para chegar no produto final. 3) Antes da finalização da palestra foram mostradas fotos de impactos ambientais gerados nestes processos. Após esta sensibilização realizou-se a pergunta: "Por que estamos aqui?". Sendo uma forma de propor a reflexão sobre o papel individual no contexto em que a sociedade esta organizada. Realizou-se uma roda de conversa para tirar eventuais dúvidas e para cada um expressar a sua opinião sobre o assunto.

\section{Trote Ecológico}

Esta atividade buscou integrar os alunos ingressantes nos cursos da UNIFESP, campus Diadema, em 2014 para realizar o plantio de dez arvores no bairro de Eldorado às proximidades da represa Billings. Esta ação foi uma iniciativa do SEMA de Diadema.

\section{Pedágio ecológico}

Neste evento, juntamente à Secretaria do Meio Ambiente de Diadema e seu Jardim Botânico, a equipe e a Comissão Organizadora distribuíram folders incentivando a conscientização, bem como mudas de plantas para os motoristas dos veículos que transitam nas proximidades da Unidade Manuel da Nóbrega, da UNIFESP. A principal temática foi a importância das árvores para a manutenção do microclima nos centros urbanos e o seu papel na reciclagem dos gases lançados pelos carros na atmosfera; bem como incentivar seu cultivo pela população, mediante orientações constantes nas cartilhas.

\section{Evento na Praca}

O evento foi realizado na "Praça da Moça", sendo esta a principal praça da cidade onde há uma grande visibilidade e circulação de pessoas. Durante o decorrer da ação os discentes aplicaram um questionário podendo extrair uma concepção quantitativa e qualitativa. Além do questionário, alguns discentes realizavam a limpeza da praça com vassouras para evidenciar a importância do cuidado com áreas de uso público. Os discentes foram instruídos a conversar com a pessoas para realizar a educação em espaços não formais. Apresenta-se o questionário que foi aplicado no item Resultados e Análise. 


\section{RESULTADOS E ANÁLISES}

\section{Mutirão de limpeza "Katasukata"}

Cerca de 40 pessoas retiraram por volta de $40 \mathrm{Kg}$ de lixo das margens da Represa Billings - este evento contou com a presença de discentes e docentes da UNIFESP - Campus, Diadema; Núcleo Pró-Vela; ONG Beija-flor; Secretaria do Meio Ambiente de Diadema e a Guarda Civil Metropolitana. A atividade foi importante para aproximar as entidades atuantes no município e proporcionar o encontro das pessoas. Após a atividade foi realizado um círculo de conversa onde obteve-se um retorno da comunidade e a apresentação do que foi refletido no local. Grande parte do material recolhido já encontravam-se em um estado inapropriado para a reciclagem. Neste sentido os envolvidos puderam notar o impacto que ocorre no ambiente dos resíduos descartados de forma inadequada. Após a coleta dos materiais montou-se uma exposição nas dependências da UNIFESP com as fotos do resíduos encontrados mais inusitados, levando aos demais discentes e docentes - aqueles que não participaram desta atividade - a realidade que os cerca; promovendo também uma reflexão sobre seu papel nesta comunidade.

\section{$\underline{\text { Pedágio Ecológico }}$}

Ao todo foram realizados dois Pedágios Ecológicos onde cerca de 60 alunos da UNIFESP saíram às ruas junto ao SEMA, vestindo coletes laranjas com o emblema do projeto e da instituição. Foram distribuídos 500 folders informativos, 450 saquinhos de lixo de carro e por volta de 600 mudas de vegetação rasteira. Os participantes foram divididos em trios para que cada um entregasse um item listado acima. No decorrer das atividades as pessoas demonstravamse felizes por estar recebendo os materiais. O folder continha, além das informações sobre RSUs, uma atividade lúdica para crianças, na tentativa de que os motoristas pudessem levá-lo para casa para que seus filhos e netos brincassem, evitando que fossem descartados sem leitura e/ou reflexão.

\section{Trote ecológico}

Neste evento foram plantadas 10 árvores nas margens da Represa Billings pelos discentes da Comissão formada para esta atividade. Os alunos ingressantes nos cursos da UNIFESP, campus Diadema, neste ano relataram a sua satisfação em relação ao plantio. Alguns disseram que foi interessante pelo fato de deixarem um legado na cidade e que iriam recordar do evento no futuro. Depois da realização do plantio, realizou-se a distribuição de folders nas residências, 
Conscientização socioambiental a respeito da geração de resíduos sólidos urbanos (RSU)

próximas à represa. O conteúdo do folder dizia a respeito a como separar os resíduos sólidos durante seu descarte. Eles foram classificados em úmidos, secos e lixos especiais. No informativo constava o dia de coleta e o telefone da Secretaria do Meio Ambiente para saber onde haviam postos de coleta para os resíduos especiais. Foram distribuídos cerca de 200 folders.

\section{Visitas às Escolas}

$\mathrm{Na}$ Escola Estadual Antônio Anchieta Foram realizadas 3 mini palestras em sala de aula com alunos do quinto e sexto ano do ensino Fundamental I; cerca de 60 alunos foram atingidos. Durante a apresentação os alunos foram questionados sobre a origem dos resíduos sólidos. A maioria das respostas obtidas foram de que as embalagens, em sua maioria, são todas recicladas; fato este que não ocorre na realidade. As falas dos alunos demonstram que a ação foi importante para eles mudarem estas concepções. Após a apresentação da aula detalhada no item Material e Métodos, os alunos disseram que as informações adquiridas foram importantes para eles repensarem seus hábitos e também para incentivá-los a tomar atitudes de forma coletiva, seja na escola ou no bairro. Foi realizada uma palestra na ONG Beija-flor, a um grupo de alunos que estava desenvolvendo um projeto com os coletores presentes nas ruas de Diadema. A atividade teve o intuito de embasar melhor os alunos para realizarem o seu projeto. Foram atingidas cerca de 15 crianças entre 8 a 15 anos de idade.

\section{Evento na Praca da Moca}

Neste evento, a Comissão composta por seis discentes, além da equipe, conversaram com os transeuntes a respeito dos resíduos sólidos e aplicaram o questionário abaixo; 57 pessoas foram atingidas. Cerca de 100 folders foram distribuídos neste evento. O propósito foi além de sensibilizar e extrair a concepções dos transeuntes sobre os resíduos sólidos, pois visava a educação em um espaço não-formal, isto é, após a aplicação do questionário, ou quando perguntavam o que se estava desenvolvendo no local. Enquanto alguns membros aplicavam o questionários, outra parte do grupo realizava a limpeza da praça com vassouras. Segue abaixo a porcentagem das respostas:

1- Para você, qual é a definição de lixo? (Indicador: definição de lixo)

a) Aquilo que se descarta após alguma atividade. 8,5\%

b) São restos de materiais que não são mais aproveitadas ao final de alguma atividade humana. $10,63 \%$

c) É tudo aquilo que não presta mais. $21,27 \%$ 
d) São materiais que sobram de alguma atividade, mas que ainda pode ser utilizado em alguma outra atividade. $58,57 \%$

2- O lixo pode ser classificado como (Indicador: tipos de lixo)

a) Não pode ser classificado $4,25 \%$

b) descartável e não descartável $10,63 \%$

c) reciclável e inorgânico $34,04 \%$

d) orgânico (restos de comida) e inorgânico (vidro, plástico, ferro) 58,57\%

3- Por que o lixo deve ser descartado corretamente? (Indicador: lixo e saúde)

a) Para evitar o aparecimento e proliferação de doenças. 51,06\%

b) apenas para manter a cidade limpa $27,65 \%$

c) para melhorar o trânsito na cidade $2,12 \%$

d) apenas para facilitar a sua coleta $21,27 \%$

4- O lixo descartado incorretamente gera algum impacto ambiental? (Indicador: lixo e ambiente)

a) ( ) não $8,51 \%$

a.( ) pois não sei para onde vai o lixo $25 \%$

b.( ) porque o lixo é reciclado pela natureza $0 \%$

c.( ) porque não existe relação entre lixo e ambiente $75 \%$

b)( ) $\operatorname{sim} 91,48 \%$

d.( ) apenas na minha casa $0 \%$

e.( ) apenas no meu bairro $6,97 \%$

f.( ) na minha cidade toda e seus arredores $93,03 \%$

5- Você se considera parte dos problemas ambientais da sua cidade? (Indicador: consciência socioambiental)

( ) $\operatorname{sim} 70.3 \% \quad$ ( ) não $29,7 \%$

\section{CONSIDERAÇÕES FINAIS}

Campanhas de conscientização sempre demonstram a necessidade de uma certa periodicidade para atingir o seu objetivo, principalmente quando trata-se da mudança de hábito e comportamento. O projeto aqui proposto procurou atingir um grande número de pessoas do município e da Universidade buscando sensibilizá-las com a problemática dos Resíduos Sólidos Urbanos (RSU's) assim como procurou medir a concepção dos indivíduos em relação ao tema. Durante o processo de desenvolvimento das ações propostas houve a aproximação da Instituição 
proponente com órgãos atuantes, como a Secretaria do Meio Ambiente e Organizações Não Governamentais.

A medida do impacto gerado nos indivíduos envolvidos com as atividades é muito subjetiva, isto fez com que repensássemos na estrutura das atividades e nos materiais a serem distribuídos nelas, da mesma forma que nos fez repensar em utilizar melhores instrumentos para medir o grau de conhecimento dos indivíduos em relação ao tema.

O projeto atuou como um divulgador das informações e conhecimentos da área de Educação Ambiental focado nos RSU's. Acredita-se que se estas ações fossem desenvolvidas em maior escala e com maiores financiamentos, elas poderiam aumentar ainda mais o seu impacto provocando maior sensibilização da população.

\section{REFERÊNCIAS}

ACURIO, G., ROSSIN, A., TEIXEIRA, P.F., ZEPETA, F., 1997. Diagnóstico de la Situación de Manejo de Residuos Sólidos Municipales en América Latina el Caribe. Banco Interamericano de Desarrollo/Organización Panamericana de la Salud, Washington, DC.

AMADOR, A.B., PALMA, L.M., 2013. Dez anos do programa voluntaries do parquet Nacional da Tijuca, RJ. Anais - Uso Público em Unidades de Conservação, n. 1, v. 1. Universidade Federal Fluminense, Niterói

BERNARD, H.R., 1988. Research Methods in Cultural Anthropology

Sagepublications: London.

BRAGA, B., HESPANHOL, I., CONEJO, J.G.L., BARROS, M.T.L., SPENCER, M., PORTO, M., NUCCI, N., JULIANO, N., EIGER, S., 2005. Introdução à Engenharia Ambiental. Prentice Hall, São Paulo.

BOGDAN, R., Biklen, S., 1994. Investigação Qualitativa em Educação, Ed. Porto: Portugal.

CARVALHO, I., 1998. As transformações da cultura e o debate ecológico: desafios políticos para uma educação ambiental, In: REIGOTA M.,Barcelos, V.H. de L. (Orgs), Tendências da Educação Ambiental Brasileira, EDUNISC, Sta. Cruz do Sul, pp. 113-126.

CATÃO, A., NEGRIN, I. Diário do Grande ABC. Disponível em: http://www.uniagua.org.br/website/default.asp?tp=1\&pag=cont_111005.htm, 2005. Acesso em 09 nov. 2013. 
CATAPRETA, C.A.A., HELLER, L., 1999. Associação entre coleta de resíduos sólidos domiciliares e saúde, Belo Horizonte (MG). Pan American JournalofPublic Health 5: 88-96.

CENTRO DE ESTUDOS ETNOBOTÂNICOS E ETNOFARMACOLÓGICOS. Disponível em: http://www.cee.unifesp.br/extensao.htm. Acesso em 09 nov. 2013.

CUIDANDO DO VERDE - AMIGOS DA NATUREZA. Disponível em: http://cuidandodoverde.blogspot.com.br/2010/02/salvem-billings.html. Acesso 11 nov. 2013. EMPLASA - Empresa Paulista de Planejamento Metropolitano. Disponível em: URL: http://www.emplasa.sp.gov.br/portalemplasa/index.asp. Acesso em: 09 nov. 2013.

GRAVINATTO, M.V., RODRIGUES, L.F., 2000. De onde vem? Para onde vai? Moderna, São Paulo.

HELLER, L., 1995. Associação entre cenários de saneamento e diarréia em Betim- MG. O Emprego do Delineamento Epidemiológico Caso-controle na Definição de Prioridade de Intervenção. Tese de Doutorado, Escola de Veterinária, Universidade Federal de Minas Gerais, Belo Horizonte.

INSTITUTO BRASILEIRO DE GEOGRAFIA ESTATÍSTICA - IBGE. Síntese de Indicadores 2006. Disponível em: http://www.ibge.gov.br/home/estatistica/populacao/trabalhoerendimento/pnad2006/. Acesso em: 08 nov. 2013.

INSTITUTO BRASILEIRO DE GEOGRAFIA ESTATÍSTICA - IBGE. Atlas Saneamento 2011. Disponível em: http:/ / saladeimprensa.ibge.gov.br/noticias?view $=$ noticia\&id=1\&busca=1\&idnoticia $=1998$. Acesso em: 08 nov. 2013.

INSTITUTO BRASILEIRO DE GEOGRAFIA ESTATÍSTICA - IBGE. Pesquisa nacional de saneamento básico. Disponível em: <http://www.ibge.gov.br/ibgeteen>. Acesso em: 08 nov. 2013.

IBGE Datasus. Disponível em: http://cidades.ibge.gov.br/xtras/perfil.php?codmun=351380. Acesso em: 08 nov. 2013.

JARDIM, N.S., WELLS, C. (Org.), 1995. Lixo Municipal: Manual de Gerenciamento integrado. IPT: CEMPRE, São Paulo.

MORAES, E. 2005. Análise textual qualitativa entendida como processo integrado de aprender, comunicar e interferir em discursos. In: Freitas, V de F., Galiazzi, M. Do C. (Orgs), Metodologia emergentes de Pesquisa em Educação Ambiental. Eds. Unijuí: Ijuí, p. 114 
MORAES, L.R.S., 1997. Aspectos Epidemiológicos relacionados aos resíduos domiciliares urbanos: Um estudo de caso. In: 19a Congresso Brasileiro de Engenharia Sanitária e Ambiental. Anais, CD-ROM. Associação Brasileira de Engenharia Sanitária e Ambiental, Foz do Iguaçu.

MUCELIN, C.A., BELLINI, M., 2008.Lixo e impactos ambientais perceptíveis no ecossistema urbano. Sociedade\&Natureza 20: 111-124.

OPS (Organización Panamericana de La Salud), 1993. Nuestro Planeta, Nuestra Salud: Informe de La Comisión de Salud y Medio Ambiente de La OMS. Publicación Científica 505. OPS, Washington, DC.

PNUD: Atlas de Desenvolvimento Humano. Disponível em: http://www.pnud.org.br/atlas/. Acesso em 7 de nov. de 2013.

PREFEITURA MUNICIPAL DE BOMBINHAS. Disponível em: http://www.bombinhas.sc.gov.br/noticias/2013/09/02/programa-lixo-zero-e-apresentado-aservidores/. Acesso em 04 nov. 2013.

PREFEITURA MUNICIPAL DE GARIBALDI. Disponível em: http://www.garibaldi.rs.gov.br/informacoes/coleta-de-lixo/. Acesso em 07 nov. 2013.

PREFEITURA MUNICIPAL DE CAMPINAS. Disponível em: http://www.campinas.sp.gov.br/governo/servicos-publicos/dlu/programa.php. Acesso em 10 nov. 2013.

PREFEITURA MUNICIPAL DE DIADEMA. Secretaria de Saúde. São Paulo. http://www.diadema.sp.gov.br/municipio/a-cidade/1783-dados-gerais.html. Acesso em 06 nov. 2013.

QUINTAS, J.S. (Org)., 2000. Pensando e praticando a Educação Ambiental na Gestão do meio ambiente. IBAMA, Brasília.

RÊGO, R.C., 1996. Destino dos Dejetos, Lixo e Diarréia infantil em uma comunidade Periurbana de Salvador, Bahia. Dissertação de Mestrado, Instituto de Saúde Coletiva, Universidade Federal da Bahia, Salvador.

RÊGO, C.F., Barreto, M.L., Killinger, C.L., 2002. O que é lixo afinal? Como pensam mulheres residentes na periferia de um grande centro urbano. Cadernos de Saúde Pública 18: 1583-1592.

REIGADA, C., REIS, M.F.DE C.T., 2004. Educação Ambiental para crianças no ambiente urbano: uma proposta de pesquisa-ação. Ciência \& Educação 10: 149-159.

SABESP. Companhia de Saneamento de Diadema. Disponível em:http://www.sabesp.com.br. Acesso em 10 nov. 2013. 
Conscientização socioambiental a respeito da geração de resíduos sólidos urbanos (RSU)

UN (United Nations). Environmentally Sound Management of solid waste and sewage-related Issue. Disponível em: http://www.un.org/esa/sustdev/agenda21 chapter21.htm. Acesso em 08 nov. 2013.

ZANETI, I.C.B.B., SÁ, L.M., 2002. Educação ambiental como instrumento de mudança na concepção de gestão dos resíduos sólidos domiciliares e na preservação do meio ambiente. Disponível em: <http://www.anppas.org.br/encontro_anual/encontro1/gt/sociedade_do_conhecimento/Zanet i\%20-\%20Mourao.pdf>. Acesso em 08 novembro 2013.

\section{AGRADECIMENTOS}

A Secretaria do meio ambiente de Diadema.

A Proex.

A Câmara Técnica de Extensão da Universidade. 